\title{
Factors Interfering With 1 Year Survival in Ovarian Cancer Patients Undergoing Cytoreductive Surgery and Hyperthermic Intraperitoneal Chemotherapy: A Case-Control Study
}

\author{
Mihai Emil Capîlna' ${ }^{1}$ Alexandra Lavinia Cozlea ${ }^{1 *}$, Etele Előd Élthes ${ }^{2}$, Alida Puia-Dumitrescu ${ }^{1}$, Costel Rad $^{3}$, Irina \\ Irimia $^{1}$ and Bogdan Moldovan ${ }^{3}$
}

${ }^{1}$ Department of Obstetrics and Gynecology, University of Medicine and Pharmacy Târgu Mureș, Romania

${ }^{2}$ Department of General Surgery, Târgu Mureș Emergency Clinical County Hospital, Romania

${ }^{3}$ Department of General Surgery, St. Constantin Hospital, Romania

Submission: February 04, 2019; Published: February 13, 2019

*Corresponding author: Alexandra Lavinia Cozlea, Department of Obstetrics and Gynecology, University of Medicine and Pharmacy Târgu Mureș, Romania

\begin{abstract}
Objective: To emphasize the main factors involved in the recurrence and death of patients diagnosed with advanced ovarian cancer treated by cytoreductive surgery and hyperthermic intraperitoneal chemotherapy.

Materials and methods: 49 patients with stage III-IV ovarian cancer who underwent cytoreductive surgery and hyperthermic intraperitoneal chemotherapy were included in a retrospective case-control study during January 2016-February 2018. Were considered pre-surgical data, aspects regarding the surgery for cytoreduction, emphasizing Peritoneal Carcinomatosis Index, multi-organ resections and Completeness of Cytoreduction Score, but also chemotherapy details; all patients were followed-up for 1 year after the surgical intervention. Patients were divided in 3 groups: Study Group 1 (SG1)-8 patients alive with recurrence, Study Group 2 (SG2)-4 patients who deceased during the first year, Control Group (CG)-37 patients disease free.
\end{abstract}

Results: We observed that mean age was close in CG and SG1 (53.7 y.o., 53.9 y.o.), and slightly higher in SG2. Most patients had prior treatment for ovarian cancer presenting a protective factor for recurrence and death (OR=0.077), together with PCI score under 20 (OR=0.166), postsurgery CC 0 score $(\mathrm{OR}=0.141)$, platinum sensitivity of the tumors cells $(\mathrm{OR}=0.117)$, performed appendectomy (OR=0.181) and omentectomy $(\mathrm{OR}=0.141)$. Main significant risk factors for relapse and death were PCI over $20(\mathrm{OR}=6.042)$ and CC1 score $(\mathrm{OR}=4.500)$.

Conclusion: A complete cytoreduction surgery and heated intraperitoneal chemotherapy are able to destroy microscopic tumor residues, existing high-quality data suggesting survival benefits due to these procedures.

Keywords: Ovarian; Cancer; Chemotherapy; Cytoreduction; Surgery; PCI; Cisplatin; HIPEC

Abbreviatations: CRS: Cytoreductive Surgery; HIPEC: Hyperthermic Intraperitoneal Chemotherapy; CG: Control Group; PCI: Peritoneal Carcinomatosis Index

\section{Introduction}

Globally, 200.000 new cases of ovarian cancer are diagnosed each year in the entire world, leading to 100.000 deaths, being the $5^{\text {th }}$ cause of death by cancer in females [1]. In Romania, the ovarian neoplasia diagnosis is established year by year in about 1850 patients, estimating that approximately 1100 will suffer death in the same year, the diagnosis being delayed due to nonspecific symptomatology and modest screening techniques, in $75 \%$ of cases existing distant metastasis [2]. Gold standard regarding the surgical intervention for the treatment of ovarian cancer is represented by cytoreductive surgery (CRS), consisting in removing all macroscopic tumor residues, being proved that global survival time is inversely proportional with the dimension of the residual tumor [3], another field research showed that patients with residual tumors $<2 \mathrm{~cm}$ presented a longer survival [4]. In addition to cytoreductive surgery, hyperthermic intraperitoneal chemotherapy (HIPEC) was recently proved extremely efficient in annihilating residual tumor cells, intraoperative administration of the chemotherapeutic agent offering an optimal perfusion of the tissue without the barrier of the postoperative adhesions, the 
surgeon being in control of the drugs distribution and peritoneal cavity exposure [5,6]. Present research follows the main factors that could be involved in relapse of the disease and death of patients, having in perspective a pre-surgical assessment, CRS and HIPEC aspects.

\section{Materials and Methods}

A retrospective case-control study was conducted between January 2016-February 2018 in the Oncologic Gynecology Department from St. Constantin Hospital, Braşov, and $1^{\text {st }}$ Department of Obstetrics and Gynecology from Târgu Mureș Emergency Clinical County Hospital, including 49 patients aged between 24 and 76 years old, diagnosed, surgically and oncologically treated for different histological types of stage III and IV ovarian cancer. Patients were followed for 1 year beginning with the moment of cytoreductive surgery (CRS) and hyperthermic intraperitoneal chemotherapy (HIPEC), in order to determine disease progress, and were divided in 3 groups depending on the prognosis: (1) Study Group 1 (SG1), formed by 8 patients who underwent the mentioned treatment for ovarian cancer with a relapse of the disease within the first year, but being alive with recurrence, (2) Study Group 2 (SG2) including 4 patients who followed the treatment but have deceased during the first year after the procedure, (3) Control Group (CG) including 37 patients who were found disease free at the end of the first year after the surgical treatment.

For all patients was evaluated the background of surgery and chemotherapy for ovarian cancer, presence of peritoneal carcinomatosis and Peritoneal Carcinomatosis Index (PCI), described in literature as the most important staging system [7]. Furthermore, were observed and gathered data regarding the surgery for cytoreduction procedures including multiorgan

Table 1: Pre-surgical assessment.

\begin{tabular}{|c|c|c|c|}
\hline & $\begin{array}{l}\text { Control Group (CG) Patients } \\
\text { Disease Free N = } 37(\%)\end{array}$ & $\begin{array}{c}\text { Study Group } 1 \text { (SG1) Patients } \\
\text { Alive with Recurrence N = } 8(\%)\end{array}$ & $\begin{array}{c}\text { Study Group } 2 \text { (SG2) Deceased } \\
\text { Patients N = } 4(\%)\end{array}$ \\
\hline \multicolumn{4}{|c|}{ Age } \\
\hline $20-40$ years old & $5(13.5)$ & $0(0)$ & $0(0)$ \\
\hline $41-60$ years old & $19(51.4)$ & $7(87.5)$ & $4(100)$ \\
\hline$>60$ years old & $13(35.1)$ & $1(12.5)$ & $0(0)$ \\
\hline Mean age & 53.7 & 53.9 & 59.2 \\
\hline \multicolumn{4}{|c|}{ Previous Surgical Treatment for Ovarian Cancer } \\
\hline Prior surgical intervention & $24(64.9)$ & $6(75)$ & $4(100)$ \\
\hline Recently diagnosed & $13(35.1)$ & $2(25)$ & $0(0)$ \\
\hline \multicolumn{4}{|c|}{ Previous Chemotherapy for Ovarian Cancer } \\
\hline Present & $16(43.2)$ & $0(0)$ & $1(25)$ \\
\hline Absent & $21(56.8)$ & $8(100)$ & $3(75)$ \\
\hline
\end{tabular}

In Table 2 can be observed aspects regarding CRS. Peritoneal carcinomatosis was found in most of the atients from CG (62.2\%), and in 50\% of patients from SG1 and SG2, while PCI was lower resections, such as intestinal, liver or gastric resections when required, omentectomy, splenectomy, appendectomy or lymphadenectomy. After performing the surgery, was appreciated the Sugarbaker's Completeness of Cytoreduction Score, showing the radicality of the surgical intervention. Referring to HIPEC aspects, were considered important the platinum sensitivity of the tumor cells and the chemotherapeutic agent used during the procedure.

Data was gathered from the medical records, collected information being processed using Microsoft Excel, while the statistical analysis was performed using Graph Pad In Stat software (GraphPad Software, Inc., San Diego, United States of America), The research comprised 2 sections, a qualitative analysis in which the variables were presented as integer and percentage values, and a section of inferential statistic analysis performed using Fisher's Exact Test in order to determine odds for each of the studied factors.

\section{Result}

First section of this study includes several aspects found in all patients divided in the three groups, data being organized depending on the moment of cytoreductive surgery: pre-surgical assessment, intraoperative aspects and chemotherapy inserted in the peritoneal cavity. Table 1 shows the pre-surgical evaluation, age being the first followed factor, most of the patients being aged between 41-60 years old in all three groups, but in different percentages. Was observed that mean age for CG (53.7 yo) was close to SG1 (53.9 yo), while in SG2 appeared to be slightly higher (59.2). Regarding the previous treatment for ovarian cancer, we observed the all patients in SG2 has a prior surgical intervention, $75 \%$ from SG1 and 64.\% from CG. Previous chemotherapy was followed by 16 patients in CG (43\%), 0 patients in SG1 and 1 patient in SG2. than 20 in the majority of patients from CG (78.4\%), and higher than 20 in most of the patients from SG1 (62.5\%) and SG2 (75\%). 
Table 2: Cytoreductive surgery - intraoperative aspects.

\begin{tabular}{|c|c|c|c|}
\hline & $\begin{array}{l}\text { Control Group (CG) Patients } \\
\text { Disease Free n = } 37(\%)\end{array}$ & $\begin{array}{c}\text { Study Group } 1 \text { (SG1) Patients } \\
\text { Alive with Recurrence } n=8(\%)\end{array}$ & $\begin{array}{c}\text { Study Group } 2 \text { (SG2) Deceased } \\
\text { Patients } n=4(\%)\end{array}$ \\
\hline \multicolumn{4}{|c|}{ Presence of Peritoneal Carcinomatosis } \\
\hline Present & $23(62.2)$ & $4(50)$ & $2(50)$ \\
\hline Absent & $14(37.8)$ & $4(50)$ & $2(50)$ \\
\hline \multicolumn{4}{|c|}{ Peritoneal Carcinomatosis Index (PCI) } \\
\hline $0-20$ & $29(78.4)$ & $3(37.5)$ & $1(25)$ \\
\hline 21-39 & $8(21.6)$ & $5(62.5)$ & $3(75)$ \\
\hline \multicolumn{4}{|c|}{ Multiorgan Resections } \\
\hline Small intestine resection & $5(13.5)$ & $1(12.5)$ & $1(25)$ \\
\hline Large intestine resection & $21(56.8)$ & $6(75)$ & $2(50)$ \\
\hline Gastrectomy & $2(5.4)$ & $0(0)$ & $0(0)$ \\
\hline Splenectomy & $12(32.4)$ & $3(37.5)$ & $2(50)$ \\
\hline Liver resection & $9(24.3)$ & $1(12.5)$ & $1(25)$ \\
\hline Diaphragm resection & $8(21.6)$ & $2(25)$ & $2(50)$ \\
\hline Appendectomy & $24(64.9)$ & $2(25)$ & $0(0)$ \\
\hline Omentectomy & $26(70.3)$ & $2(25)$ & $0(0)$ \\
\hline Lymphadenectomy & $20(54.1)$ & $3(37.5)$ & $2(50)$ \\
\hline \multicolumn{4}{|c|}{ Completeness of Cytoreduction Score } \\
\hline $\mathrm{CCO}$ & $26(70.3)$ & $2(25)$ & $1(25)$ \\
\hline CC1 & $10(27)$ & $5(62.5)$ & $2(50)$ \\
\hline $\mathrm{CC} 2$ & $1(2.7)$ & $1(12.5)$ & $1(25)$ \\
\hline Postoperative complications & $5(13.5)$ & $0(0)$ & $0(0)$ \\
\hline
\end{tabular}

Large intestine resections were highly performed in all three study groups, in $56.8 \%$ of patients from CG, $75 \%$ from SG1 and $50 \%$ in SG2, lymphadenectomy in $54.1 \%$ from the total of patients in CG, $37.5 \%$ in SG1and $50 \%$ in SG2, while splenectomy was completed in high percentage in all groups, $32.4 \%$ in CG, $37.5 \%$ in SG1 and 50\% for SG2. Was observed that some of the procedures were highly performed in CG, but in low percentages in SG1 and SG2: omentectomy was executed in $70.3 \%$ of patients from CG and appendectomy in $64.9 \%$ of cases. Small intestine resection, gastrectomy, liver and diaphragm resections were not performed by routine, as shown by the low percentages of patients from the three groups who benefited from these procedures. Cytoreduction score was CC0 in most of the patients from CG, while CC1 was obtained for the majority of patients from SG1 (62.5\%) and SG2 (50\%). CC2 was observed for 1 patient in each group. Postoperative

Table 3: Hyperthermic Intraperitoneal Chemotherapy aspects.

\begin{tabular}{|c|c|c|c|}
\hline \multicolumn{5}{|c|}{} & $\begin{array}{c}\text { Control Group (CG) Patients } \\
\text { Disease Free n = 37 (\%) }\end{array}$ & $\begin{array}{c}\text { Study Group 1 (SG1) Patients } \\
\text { Alive with Recurrence n = 8 (\%) }\end{array}$ & $\begin{array}{c}\text { Study Group 2 (SG2) Deceased } \\
\text { Patients n = 4 (\%) }\end{array}$ \\
\hline \multicolumn{2}{|c|}{ Platinum Sensitivity } \\
\hline Sensitive & $31(83.8)$ & $3(37.5)$ & $5(25)$ \\
\hline Resistant & $6(16.2)$ & $5(62.5)$ & $3(75)$ \\
\hline \multicolumn{7}{|c|}{ Chemotherapeutic Agent } \\
\hline Cisplatin & $25(67.6)$ & $3(37.5)$ & $1(25)$ \\
\hline Doxorubicin & $12(32.4)$ & $5(62.5)$ & $3(75)$ \\
\hline
\end{tabular}

complications were noted in $13.5 \%$ from CG, while in SG1 and SG2 were not observed post-surgery difficulties.

Table 3 presents the results observed regarding the HIPEC procedure. Platinum sensitivity of the tumoral cells was found in $83.8 \%$ of cases from CG, while platinum resistant tumors were noted in the majority of patients belonging to SG1 (62.5\%) and SG2 (75\%). In 67.6\% of patients from CG was preferred Cisplatin as the chemotherapy agent for HIPEC, Doxorubicin being used mostly in SG1 (62.5\%) and SG2 (75\%). In Table 4 can be observed the results for the inferential statistical analysis, represented by odds ratios and P values. Regarding the age of patients, the highest risk in patients with ovarian cancer is the interval 41-60 years old with an $\mathrm{OR}=6.632(\mathrm{P}=0.045)$ for recurrence, and $\mathrm{OR}=0.05$ $(\mathrm{P}=0.05)$ for decease. 


\section{Journal of Gynecology and Women's Health}

Table 4: Factors involved in recurrence and death in patients with ovarian cancer.

\begin{tabular}{|c|c|c|c|c|}
\hline \multirow[b]{2}{*}{ Variable } & \multicolumn{2}{|c|}{ Study Group 1 (SG1) in Relation to Control Group (CG) } & \multicolumn{2}{|c|}{ Study Group 2 (SG2) in Relation to Control Group (CG) } \\
\hline & Odds Ratio & P Value & Odds Ratio & P Value \\
\hline \multicolumn{5}{|c|}{ Age } \\
\hline $20-40$ years old & 0.348 & NS & 0.657 & NS \\
\hline $41-60$ years old & 6.632 & 0.045 & 8.538 & 0.05 \\
\hline$>60$ years old & 0.264 & NS & 0.202 & NS \\
\hline Previous surgical treatment & 1.625 & NS & 4.959 & NS \\
\hline $\begin{array}{l}\text { Presence of previous } \\
\text { chemotherapy }\end{array}$ & 0.077 & 0.0366 & 0.4375 & NS \\
\hline \multicolumn{5}{|c|}{ Peritoneal Carcinomatosis Index (PCI) } \\
\hline $0-20$ & 0.166 & 0.0338 & 0.092 & 0.05 \\
\hline 21-39 & 6.042 & 0.0338 & 10.875 & 0.05 \\
\hline \multicolumn{5}{|c|}{ Multiorgan Resections } \\
\hline Intestinal resection & 2.962 & NS & 1.269 & NS \\
\hline Splenectomy & 1.25 & NS & 2.083 & NS \\
\hline Liver resection & 0.444 & NS & 1.037 & NS \\
\hline Diaphragm resection & 1.208 & NS & 3.625 & NS \\
\hline Appendectomy & 0.181 & 0.05 & 0.061 & 0.0235 \\
\hline Omentectomy & 0.141 & 0.0388 & 0.048 & 0.0135 \\
\hline Lymphadenectomy & 0.51 & NS & 0.85 & NS \\
\hline \multicolumn{5}{|c|}{ Completeness of Cytoreduction Score } \\
\hline $\mathrm{CCO}$ & 0.141 & 0.0388 & 0.141 & NS \\
\hline CC1 & 4.5 & 0.05 & 2.7 & NS \\
\hline CC2 & 5.143 & NS & 12 & NS \\
\hline \multicolumn{5}{|c|}{ Platinum Sensitivity } \\
\hline Sensitive & 0.117 & 0.0141 & 0.064 & 0.0278 \\
\hline Resistant & 8.611 & 0.0141 & 15.5 & 0.0278 \\
\hline \multicolumn{5}{|c|}{ Chemotherapeutic Agent } \\
\hline Cisplatin & 0.288 & NS & 0.16 & NS \\
\hline Doxorubicin & 3.472 & NS & 6.25 & NS \\
\hline
\end{tabular}

NS = not significant $P$ value $(>0.05)$.

For existing previous chemotherapy was calculated a statistically significant $\mathrm{OR}=0.077$ for recurrence. PCI under 20 showed an $\mathrm{OR}=0.166(\mathrm{P}=0.0338)$ for recurrence and $\mathrm{OR}=0.092$ $(\mathrm{P}=0.05)$ for death, while for an index over 20 was calculated $\mathrm{OR}$ was 6.042 for recurrence $(\mathrm{P}=0.0338)$ and 10.875 for deceased patients $(\mathrm{P}=0.05)$. Statistical significance regarding the performed surgical procedures during CRS was determined for omentectomy with an $\mathrm{OR}=0.141 \quad(\mathrm{P}=0.0388)$ for patients with recurrence and $\mathrm{OR}=0.048(\mathrm{P}=0.0135)$ for patients who suffered death, and appendectomy, $\mathrm{OR}=0.181$ for relapsed patients $(\mathrm{P}=0.05)$ and $\mathrm{OR}=0.061$ for deceased patients $(\mathrm{P}=0.0235)$.

Completeness of cytoreduction was a statistically significant factor as respects CC0, with a statistically significant $\mathrm{OR}=0.141$ for relapse $(\mathrm{P}=0.0388)$ and an $\mathrm{OR}=0.141$ for decease, but without statistical significance. For CC1 was observed an $\mathrm{OR}=4.500$ $(\mathrm{P}=0.05)$ for patients alive with recurrence, and an $\mathrm{OR}=2.700)$ for deceased patients, but with no statistical significance. For CC2 were not found significant results from the statistical perspective.

Platinum sensitivity showed extremely significant statistical results. For platinum sensitive tumor cells OR was 0.117 for patients with recurrence and 0.064 for patients who suffered death, while for platinum resistant tumors was 8.611 for relapsed patients and 15.500 for decease. The type of chemotherapeutic agent used in HIPEC procedure was proved not to be relevant from the statistical perspective.

\section{Discussion}

Pre-surgical assessment revealed interesting results, but also comparable to specialty literature. Age of patients was the first studied factor and according to our study, advanced age of patients treated for ovarian cancer proved to be an important and significant risk factor for disease relapse, being even more 
importantly linked to decease of patients, shortening the survival time, and according to other published reports, advanced age significantly increases the morbidity after CRS and HIPEC [8]. Pathological ovarian cancer-related background was evaluated in order to establish which factor from prior therapy for this disease could influence the patients' survival. Previous surgical treatment presented a low risk for relapse but a high risk for death, none of the values being statistically significant, but previous published studies affirm that a newly diagnosed ovarian cancer is associated with a longer survival, the most significant element for a prolonged survival being the first cytoreductive surgery [9]. According to our results, prior systemic chemotherapy was a statistically significant protective factor towards both of disease relapse and death, these being in accordance to previous published researches which affirm that the addition of HIPEC to cytoreductive surgery and systemic chemotherapy significantly improves survival in patients with ovarian cancer, both primary and recurrent [10].

The standard surgical treatment for ovarian cancer is maximal cytoreductive surgery with standard peritonectomy procedures, removing all macroscopic disease, for which a staging system as PCI is vital. Our study shows that PCI values under 20 are a significant protective factor for both recurrence and death, assuring a longer survival in patients with ovarian cancer, while scores over 20 are associated with high odds ratios for recurrence, and higher for decease; previous reports also affirm that a lower PCI score combined with the ability to resect all macroscopic disease appear to be correlated with an overall survival advantage [11].

Cytoreductive surgery for ovarian cancer requires in the majority of cases multiorgan resections. According to our study, small and large intestine resections did not show statistically significant involvement in the prognosis of patients, but literature of specialty affirms that the necessity of intestinal resections during CRS could be an independent factor associated with major morbidity [12]. Regarding splenectomy as a component of CRS, previous authors stated that this procedure can be performed safely with acceptable rates of morbidity and mortality [13], but in the present study were not found relevant statistical results involving splenectomy as a cytoreductive procedure. Same results without statistical significance were also observed related to liver resection during CRS, our outcomes being in contradiction to other authors' reports, according to which in selected cases, liver resection in patients with ovarian cancer with liver metastasis could be associated with an important increase of overall survival [14].

The resection of the diaphragm is reported by other authors to be safe and feasible in case of liver-diaphragmatic metastatic lesions in patients with ovarian cancer [15], previous researches reporting that the resection of the diaphragmatic disease is not increasing significantly the morbidity rates [16]; contrary to published reports, our results did not show statistical significance regarding the diaphragm resection during CRS in patients with ovarian cancer. According to our research, performed appendectomy resulted to be a statistically significant protective factor for recurrence in the first year after CRS and HIPEC, and also for death, previous published studies reporting that appendectomy is extremely appropriate for contributing to maximal cytoreduction in advanced ovarian cancer cases [17]. Another surgical procedure which according to the present research showed important statistical results was omentectomy, that could be also considered a protective factor towards relapse and decease, in relation to patients disease free, a previous rat study suggesting the possibility that the omentum is involved in retaining tumor cells, the timing of omentectomy requesting precaution and reconsideration in the absence of metastasis [18]. Lymphadenectomy was performed in the present research in most of the patients during CRS, but the calculated values for odds ratio did not show a statistical relevance, these findings being in contradiction to other authors' outcome, which affirm that lymphadenectomy has a great effect on progression-free survival and recurrence rate in patients with advanced ovarian cancer [19].

Completeness of Cytoreduction Score is considered in literature an important prognosis factor. In our study, patients in which optimal resection was obtained, $\mathrm{CC} 0$, presented a protective factor for recurrence and decease, while CC1 proved to be a statistically significant risk factor for relapse, these results being in accordance to other published studies, which reported that the completeness of cancer resection is an independent predictor of the favorable prognosis [20].

Chemotherapy aspects are extremely important in CRS and HIPEC procedures. For the studied patients, was observed that platinum sensitive tumor cells were a significant protective factor for recurrence and death during the first year of followup, but recent retrospective, case-control studies and metaanalysis affirmed that heat may help the penetration of the chemotherapeutic agent into nearby tissues, patients treated with CRS and HIPEC with platinum resistant cell lines could have a similar survival to those with platinum sensitive disease. The type of the chemotherapeutic agent was not statistically relevant according to our results.

\section{Conclusion}

Using CRS and HIPEC in the treatment of stage III-IV ovarian cancer is a strong reason due to the multiple survival benefits that these procedures bring, especially in patients with advanced age. The absence of effective screening methods and programs lead to a difficult diagnosis, often in advanced staged, with peritoneal carcinomatosis and multiorgan metastasis. A complete cytoreduction surgery and heated intraperitoneal chemotherapy are able to destroy microscopic tumor residues, existing highquality data suggesting survival benefits due to these procedures. The present study proves the importance of PCI in order to predict the prognosis, but also of the multi-organ resections performed during CRS, emphasizing the effects of appendectomy, omentectomy and lymphadenectomy on the favorable prognosis of 
patients with ovarian cancer, while intestinal, liver and diaphragm resections, together with splenectomy needing a larger amount of cases to be more precisely studied. In addition, was proved the crucial importance of the Completeness of Cytoreduction Score, a complete resection being able to substantially contribute in extending the survival time for patients suffering from this disease, together with an appropriate chemotherapeutic agent administered during HIPEC procedure. In conclusion, we can affirm that CRS and HIPEC could be used on a large scale in primary management of ovarian cancer, prolonging overall survival and life quality.

\section{References}

1. Bhatt A, Glehen $O$ (2016) The role of cytoreductive surgery and hyperthermic intraperitoneal chemotherapy (HIPEC) in ovarian cancer: a review. Indian J Surg Oncol 7(2): 188-197.

2. Sun JH, Ji ZH, Yu Y, Wu HT, Huang CQ et al. (2016) Cytoreductive surgery plus hyperthermic intraperitoneal chemotherapy to treat advanced/ recurrent epithelial ovarian cancer: Results from a retrospective study on prospectively established database. Translational Oncology 9(2): 130-138.

3. Griffiths CT (1975) Surgical resection of tumor bulk in the primary treatment of ovarian carcinoma. Natl Cancer Inst Monogr 42: 101-104.

4. Hoskins WJ, McGuire WP, Brady MF, Homesley HD, Creasman WT, et al. (1994) The effect of diameter of largest residual disease on survival after primary cytoreductive surgery in patients with suboptimal residual epithelial ovarian carcinoma. J Obstet Gynecol 170(4): 974979.

5. Giorgio DA, Naticchioni E, Biacchi D, Sibio S, Accarpio F, et al. (2008) Cytoreductive surgery (peritonectomy procedures) combined with hyperthermic intraperitoneal chemotherapy (HIPEC) in the treatment of diffuse peritoneal carcinomatosis from ovarian cancer. Cancer 113(2): 315-325.

6. Huo YR, Richards A, Liauw W, Morris DL (2015) Hiperthermic intraperitoneal chemotherapy (HIPEC) and cytoreductive surgery (CRS) in ovarian cancer: A systematic review and meta-analysis. Eur J Surg Oncol 41(12): 1578-1589.

7. Portilla AG, Kusamura S, Baratti D, Deraco M (2008) The intraoperative staging system in the management of Peritoneal surface malignancy. J Surg Oncol 98(4): 228-231.

8. Roviello F, Marrelli D, Neri A, Cerretani D, Manzoni DG, et al. (2006) Treatment of peritoneal carcinomatosis by cytoreductive surgery and intraperitoneal hyperthermic chemoperfusion (IHCP): postoperative outcome and risk factors for morbidity. World J Surg 30(11): 20332040.
9. Cotte E, Glehen O, Mohamed F, Lamy F, Falandry C, et al. (2007) Cytoreductive surgery and intraperitoneal chemo-hyperthermiafor chemo-resistant and recurrent advanced epithelial ovarian cancer: prospective study of 81 patients. World J Surg 31(9): 1813-1820.

10. Bhatt A, Glehen $O$ (2016) The role of cytoreductive surgery and hyperthermic intraperitoneal chemotherapy (HIPEC) in ovarian cancer: A review. Indian J Surg Oncol 7(2): 188-197.

11. Reichman TW, Cracchiolo B, Sama J, Bryan M, Harrison J, et al. (2005) Cytoreductive surgery and intraoperative hyperthermic chemoperfusion for advanced ovarian carcinoma. J Surg Oncol 90(2): 51-56.

12. Cascales CP, Gil J, Parrilla P (2014) Morbidity and mortality outcomes of cytoreductive surgery and hyperthermic intraperitoneal chemotherapy in patients with primary and recurrent advanced ovarian cancer. Eur J Surg Oncol 40(8): 970-975.

13. Bacalbasa N, Balescu I, Dima S, Brasoveanu V, Popescu I, et al. (2015) Splenectomy as part of cytoreductive surgery in recurrent epithelial ovarian cancer. Anticancer Res 35(9): 5097-5101.

14. Bacalbasa N, Balescu I, Dima S, Popescu I (2015) Long-term survivors after liver resection for ovarian cancer liver metastasis. Anticancer Res 35(12): 6919-6923.

15. Xu YY, Lu X, Mao YL, Xiong JP, Bian J, et al. (2017) The surgical treatment of ovarian cancer metastasis between liver and diaphragm: a report of 83 cases. Zhonghua Wai Ke Za Zhi 55(11): 838-841.

16. Pounds R, Phillips A, Kehoe S, Nevin J, Sundar S, et al. (2018) Diaphragm disease in advanced ovarian cancer: Predictability of pre-operative imaging and safety of surgical intervention. Eur J Obstet Gynecol Reprod Biol 226: 47-53.

17. Ayhan A, Tuncer ZS, Tuncer R, Yüce K, Ayhan A, et al. (1994) Is routine appendectomy beneficial in the management of ovarian cancer? Eur J Obstet Gynecol Reprod Biol 57(1): 29-31.

18. Yokoyama Y, Hirakawa H, Wang H, Mizunuma H (2012) Is omentectomy mandatory in the operation for ovarian cancer? Preliminary results in a rat study. Eur J Obstet Gynecol Reprod Biol 164(1): 89-92.

19. Zhou J, Shan G, Chen Y (2016) The effect of lymphadenectomy on survival and recurrence in patients with ovarian cancer: a systematic review and meta-analysis. Jon J Clin Oncol 46(8): 718-726.

20. Arjona-Sanchez A, Rufian-Pena S, Artiles M, Sanchez-Hidalgo JM, Casado-Adam A, etal. (2018) Residual tumor less than 0.25 centimetres and positive lymph nodes are risk factors for early relapse in recurrent ovarian peritoneal carcinomatosis treated with cytoreductice surgery, HIPEC, and systemic chemotherapy. Int J Hyperthermia 34(5): 570577. 
(CC) This work is licensed under Creative BY DOI: 10.19080/JGWH.2019.14.555881

\section{Your next submission with Juniper Publishers} will reach you the below assets

- Quality Editorial service

- Swift Peer Review

- Reprints availability

- E-prints Service

- Manuscript Podcast for convenient understanding

- Global attainment for your research

- Manuscript accessibility in different formats

( Pdf, E-pub, Full Text, Audio)

- Unceasing customer service

Track the below URL for one-step submission https://juniperpublishers.com/online-submission.php 